\title{
Phase behavior and miscible mechanism in the displacement of crude oil with associated sour gas
}

\author{
Congge He*, Longxin Mu, Anzhu Xu, Lun Zhao, Jun He, Angang Zhang, Fachao Shan, and Erhui Luo \\ Research Institute of Petroleum Exploration and Development, PetroChina, 20 Xueyuan Road, Haidian, Beijing 100083, China
}

Received: 3 January 2019 / Accepted: 11 April 2019

\begin{abstract}
The re-injection of associated sour gas, with high $\mathrm{H}_{2} \mathrm{~S}$ and $\mathrm{CO}_{2}$ content, into the reservoir is proposed to be an effective development method due to its low investment cost and high oil recovery. The aim of this work is to present the phase behavior and miscible mechanism of crude oil displaced by associated sour gas. Based on the equation of state and the phase equilibrium theory, the phase behavior of crude oil mixed with various gases (associated sour gas, $\mathrm{H}_{2} \mathrm{~S}, \mathrm{CO}_{2}$ and $\mathrm{CH}_{4}$ ) have been analyzed. Then, the miscibility of associated sour gas was determined by calculating its Minimum Miscible Pressure (MMP) and the effect of sour component fraction on miscibility was evaluated. Moreover, a series of numerical simulations modeling 1D slim-tube were conducted using a compositional simulator to study the miscible mechanism in the displacement of crude oil with associated sour gas. The results show that the injection of $\mathrm{H}_{2} \mathrm{~S}$ can reduce the bubble point pressure of crude oil and therefore is beneficial to prevent the crude oil degassing; nevertheless, the injection of $\mathrm{CO}_{2}$ has little effect on it. The miscible ability of associated sour gas decreases as its sour component fraction decreases. It is observed that the crude oil displaced by associated sour gas and sweet gas both show a combined condensing/vaporizing mechanism, with miscible zone in the middle of transition zone. However, the vaporizing-gas drive mechanism is slightly stronger than the condensing-gas drive mechanism during the displacement by associated sour gas while is significantly stronger during the displacement by sweet gas.
\end{abstract}

\section{Introduction}

Gas injection to improve oil recovery has been researched and successfully applied in many oil fields all over the world for almost one half century (Arne et al., 2000; Chen, 1995; Knut and Lars, 2002; Murty and Al-Khayat, 1989; Teletzke et al., 2005; Zhang et al., 2013). Gas injection not only is a pressure maintenance program, which can support the reservoir pressure and thereby increase the rate of oil production, but also is an important way for enhanced oil recovery by achieving miscibility (Tang et al., 2001; Zakaria, 2011; Zhu et al., 2015). Recently, the most common injection mediums are hydrocarbon, $\mathrm{CO}_{2}, \mathrm{~N}_{2}$ and flue gas (Chen et al., 2011; Kulkarni and Rao, 2005; Meng et al., 2018). Guo (Guo et al., 2000) researched the influence of injection gas $\left(\mathrm{CO}_{2}, \mathrm{~N}_{2}, \mathrm{CH}_{4}\right.$ and flue gas) on physical behavior of crude oil.

The mechanisms of miscibility have been extensively discussed in literature (Johns et al., 1994, Li et al., 2006; Tang et al., 2004; 2005). Traditionally, the crude oil displaced by injected gas may achieve miscibility in two ways: condensing-gas drive mechanism and vaporizing-gas drive

\footnotetext{
* Corresponding author: hecongge1988@163.com
}

mechanism. When the gas is rich in intermediate component, the intermediate component in the gas will condense into the crude oil thus making the oil richer and richer, until it becomes rich enough to be miscible with the fresh injected gas. The condensing-gas drive process is shown in Figure 1a. The miscible zone of condensing-gas drive is located behind the immiscible zone (two-phase region). However, in the vaporizing-gas drive process, the intermediate component of the crude oil is stripped into the gas, which makes the gas richer and richer. Eventually, if the crude oil is rich enough, the gas becomes so enriched with the intermediate component that it becomes miscible with the original crude oil. The vaporizing-gas drive process is shown in Figure 1b. The miscible zone of vaporizing-gas drive is located on the front of the immiscible zone. The crude oil displaced by enriched gas can display features of both condensing and vaporizing drives (Stalkup, 1987; Zick, 1986). They pointed out that above an apparent minimum miscibility pressure, the condensing/vaporizing mechanism can generate displacements that are effectively miscible, although true miscibility may not actually be developed.

The re-injection of associated sour gas, with high $\mathrm{H}_{2} \mathrm{~S}$ and $\mathrm{CO}_{2}$ content, are being conducted in many reservoirs, 


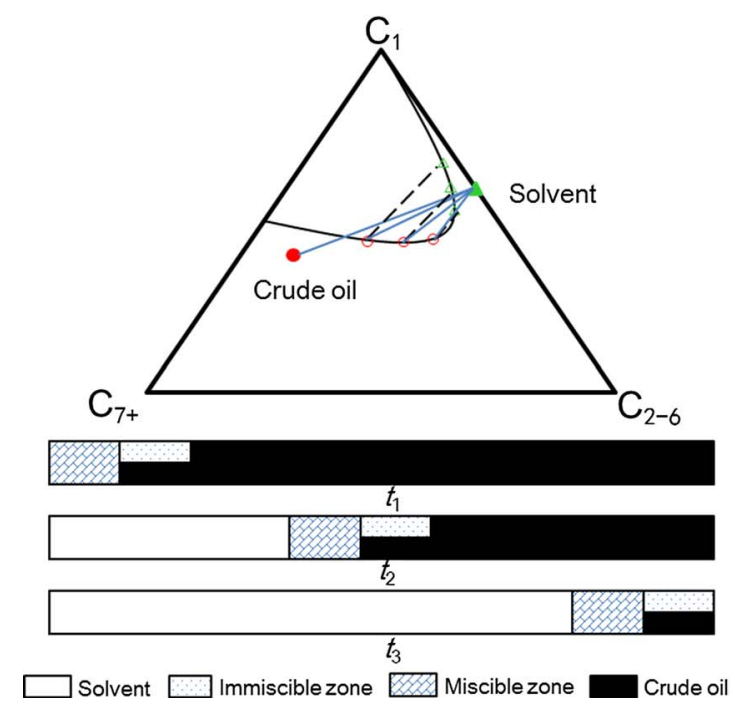

(a) condensing-gas drive

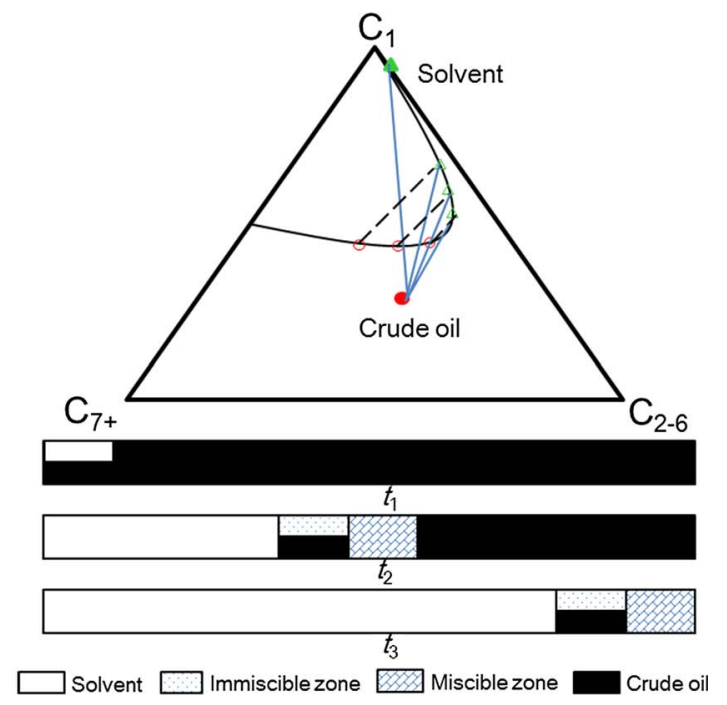

(b) vaporizing-gas drive

Fig. 1. Classic miscible mechanism schematic.

such as Tengiz oil field in western Kazakhstan (Sabyrzhan et al., 2010). On the one hand, the re-injection of associated sour gas can reduce the investment cost as the desulphurization equipment is not required. On the other hand, it can maintain the reservoir pressure and realize miscibility, thus achieving high oil recovery (Xu et al., 2015; Zhang et al., 2016). High $\mathrm{H}_{2} \mathrm{~S}$ and $\mathrm{CO}_{2}$ content in associated sour gas may make the phase behavior and miscible mechanism different from usually injected gas, such as pure $\mathrm{CO}_{2}$, pure $\mathrm{CH}_{4}$ and enriched gas. The main focus of this paper is to investigate the phase behavior and miscible mechanism of crude oil displaced by associated sour gas. In this paper, the phase behavior of crude oil mixed with various gases (associated sour gas, $\mathrm{H}_{2} \mathrm{~S}, \mathrm{CO}_{2}$ and $\mathrm{CH}_{4}$ ) was firstly analyzed based on the equation of state and the phase equilibrium theory. Then, the miscibility of associated sour gas was determined and the effect of sour component fraction on miscibility was evaluated. Moreover, a series of numerical simulations modeling 1D slim-tube were conducted to present the miscible mechanism in the displacement of crude oil with associated sour gas. On the basis, the effect of pressure and injected gas composition (associated sour gas, sweet gas and $\mathrm{CH}_{4}$ ) on miscibility was analyzed in detail.

\section{Phase behavior analysis}

The crude oil of K oil field in Kazakhstan was divided into nine pseudo-components according to its characterization. The composition of crude oil and associated sour gas are given in Table 1. The $\mathrm{C}_{20+}$ fraction of the crude oil has a molar mass about $437.91 \mathrm{~g} / \mathrm{mol}$ and density about $907 \mathrm{~kg} / \mathrm{m}^{3}$. Table 1 shows that the crude oil is sour containing approximately $14.69 \% \mathrm{H}_{2} \mathrm{~S}$ and $4.12 \% \mathrm{CO}_{2}$. The associated sour gas, which is re-injected into the reservoir to enhance oil recovery, contains $17.42 \% \quad \mathrm{H}_{2} \mathrm{~S}$ and $4.92 \%$
$\mathrm{CO}_{2}$. The bubble point of crude oil is about $28 \mathrm{MPa}$ at the reservoir temperature of $373.15 \mathrm{~K}$.

Based on the software of Eclipse PVTi developed by Schlumberger, the critical parameters of EOS for each component are obtained through fitting PVT experimental results. Figure 2 shows that the fitting results coincide with the experimental data very well. The critical parameters of EOS for each component are presented in Table 1.

Based on the phase equilibrium model (Chueh and Prausnitz, 1967; Obut et al., 1986; Yang and Wei, 2004) and SRK equation of state (Soave, 1972), the phase behavior of crude oil mixed with various gases (associated sour gas, $\mathrm{H}_{2} \mathrm{~S}, \mathrm{CO}_{2}$ and $\mathrm{CH}_{4}$ ) was performed as shown in Figure 3 . The injection gas mole fraction $(f)$ is 0.3 , which is defined as the mole ratio of injection gas and crude oil. Figure 3 shows that the critical point of crude oil after injecting gas moves closer to original reservoir conditions (the original reservoir temperature and pressure are $373.15 \mathrm{~K}$ and $77.8 \mathrm{MPa}$ respectively). For example, the critical temperature and pressure of crude oil are $592 \mathrm{~K}$ and 28.4 $\mathrm{MPa}$ and they move to $518 \mathrm{~K}$ and $33.1 \mathrm{MPa}$ after injecting associated sour gas. It means that the crude oil becomes more volatile after injecting gas. Figure 3 also indicates that the two-phase region becomes narrower after injecting $\mathrm{H}_{2} \mathrm{~S}$ and becomes wider after injecting $\mathrm{CH}_{4}$. Whereas, the two-phase region changes little after injecting associated sour gas and injecting $\mathrm{CO}_{2}$. For instance, the bubble point pressure of crude oil decreases from $28 \mathrm{MPa}$ to $21.8 \mathrm{MPa}$ after injecting $\mathrm{H}_{2} \mathrm{~S}$ and increases to 37.8 after injecting $\mathrm{CH}_{4}$ at the reservoir temperature. The bubble point pressure of crude oil after injecting associated sour gas and injecting $\mathrm{CO}_{2}$ are $30.1 \mathrm{MPa}$ and $29.2 \mathrm{MPa}$ at the reservoir temperature, respectively. From the analysis, it is demonstrated that the injection of $\mathrm{H}_{2} \mathrm{~S}$ can reduce the bubble point pressure of crude oil and therefore is beneficial to prevent the crude oil degassing; nevertheless, the injection of $\mathrm{CO}_{2}$ has little effect on it. 
Table 1. The pseudo-composition of crude oil and associated sour gas and the critical parameters of EOS.

\begin{tabular}{lcccccccc}
\hline Components & $\begin{array}{c}\text { Oil } \\
\text { composition } \\
(\mathrm{mol} \%)\end{array}$ & $\begin{array}{c}\text { Solution gas } \\
\text { composition } \\
(\mathrm{mol})\end{array}$ & $\begin{array}{c}\text { Molecular } \\
\text { weight } \\
(\mathrm{g} / \mathrm{mol})\end{array}$ & $\begin{array}{c}P_{\mathrm{c}} \\
(\mathrm{MPa})\end{array}$ & $\begin{array}{c}T_{\mathrm{c}} \\
(\mathrm{K})\end{array}$ & $\begin{array}{c}\text { Omega } \\
\mathrm{A}\end{array}$ & $\begin{array}{c}\text { Omega } \\
\mathrm{B}\end{array}$ & $\begin{array}{c}\text { Acentic } \\
\text { factor }\end{array}$ \\
\hline $\mathrm{H}_{2} \mathrm{~S}$ & 14.69 & 17.42 & 34.08 & 8.94 & 373.6 & 0.5 & 0.1 & 0.1 \\
$\mathrm{CO}_{2}$ & 4.12 & 4.92 & 44.01 & 7.39 & 304.7 & 0.49 & 0.07 & 0.23 \\
$\mathrm{C}_{1}$ & 49.36 & 59.03 & 16.04 & 4.6 & 190.6 & 0.43 & 0.07 & 0.01 \\
$\mathrm{C}_{2}$ & 7.32 & 8.7 & 30.07 & 4.88 & 305.4 & 0.49 & 0.07 & 0.1 \\
$\mathrm{C}_{3-4}$ & 7.22 & 8.05 & 49.81 & 4.08 & 411.1 & 0.48 & 0.11 & 0.17 \\
$\mathrm{C}_{5-6}$ & 3.04 & 1.72 & 77.11 & 3.26 & 498.9 & 0.45 & 0.11 & 0.26 \\
$\mathrm{C}_{7-10}$ & 6.5 & 0.16 & 113.34 & 2.7 & 743.9 & 0.51 & 0.09 & 0.34 \\
$\mathrm{C}_{11-20}$ & 5.34 & 0 & 190.08 & 1.93 & 754.4 & 0.43 & 0.09 & 0.51 \\
$\mathrm{C}_{20+}$ & 2.41 & 0 & 437.91 & 1.22 & 909.4 & 0.46 & 0.08 & 0.8 \\
\hline
\end{tabular}

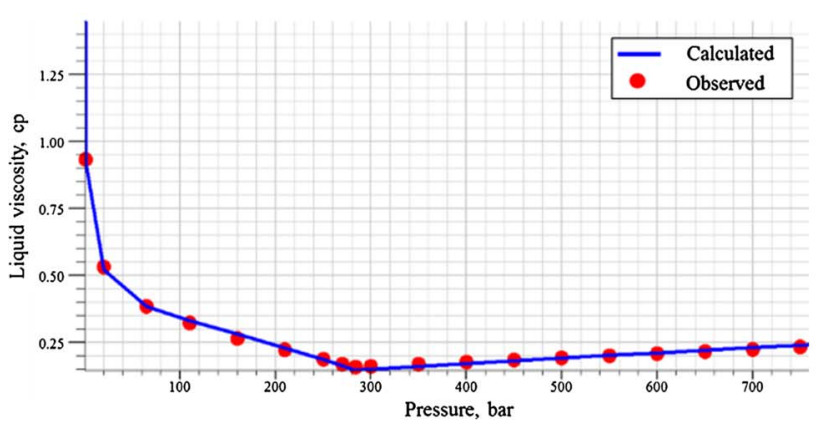

(a) liquid viscosity

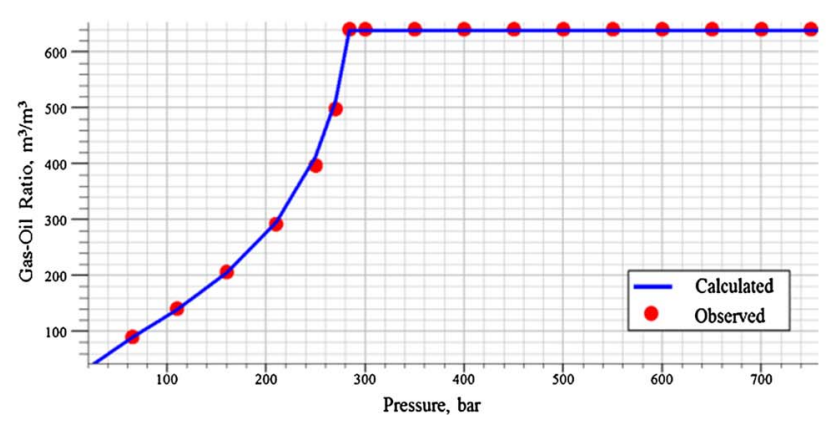

(c) Gas-oil ratio

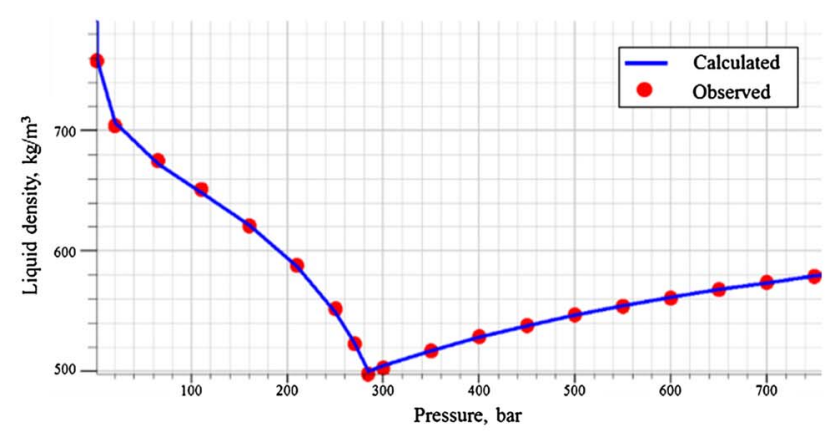

(b) liquid density

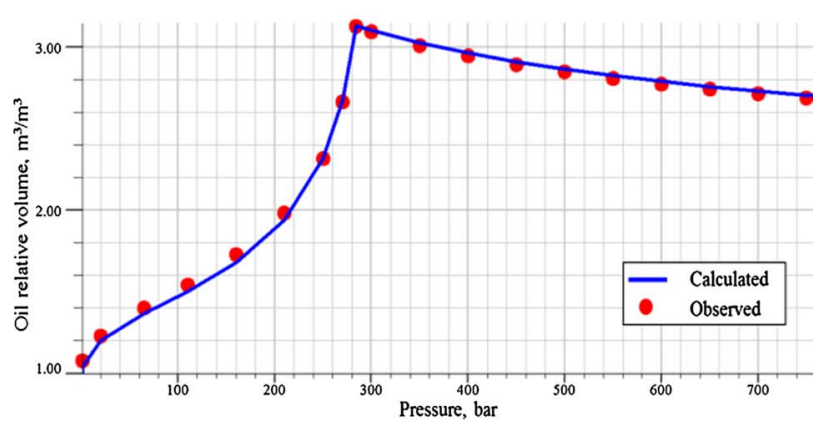

(d) Oil relative volume

Fig. 2. The fitting of PVT experimental results.

The influence of injection gas mole fraction on the phase behavior of crude oil is shown in Figure 4. It indicates that the critical point of crude oil moves closer to original reservoir conditions when the injection gas mole fraction is greater; that is, the greater the injection gas mole fraction, the crude oil becomes more volatile. The green line within the two phase region in Figure 4 represents constant liquid saturation and its value is $50 \%$. It can be easily found in Figure 4 that the pressure differentials between the bubble point pressure and the pressure crossing the $50 \%$ liquid saturation line at the reservoir temperature are $11.9 \mathrm{MPa}$, 8.5 $\mathrm{MPa}$ and 4.8 $\mathrm{MPa}$ with the injection gas mole fraction of $0,0.3$ and 0.5 , respectively. It means the shrinkage of crude oil becomes higher when the injection gas mole fraction is greater. Higher shrinkage is caused by a greater concentration of intermediate hydrocarbons in crude oil due to more gas injection.

\section{Miscible mechanism analysis}

\subsection{Minimum Miscible Pressure (MMP)}

Minimum Miscible Pressure (MMP) is a key parameter in the design of gas flooding. Recently, there are several methods available to calculate MMP. Experimental methods 


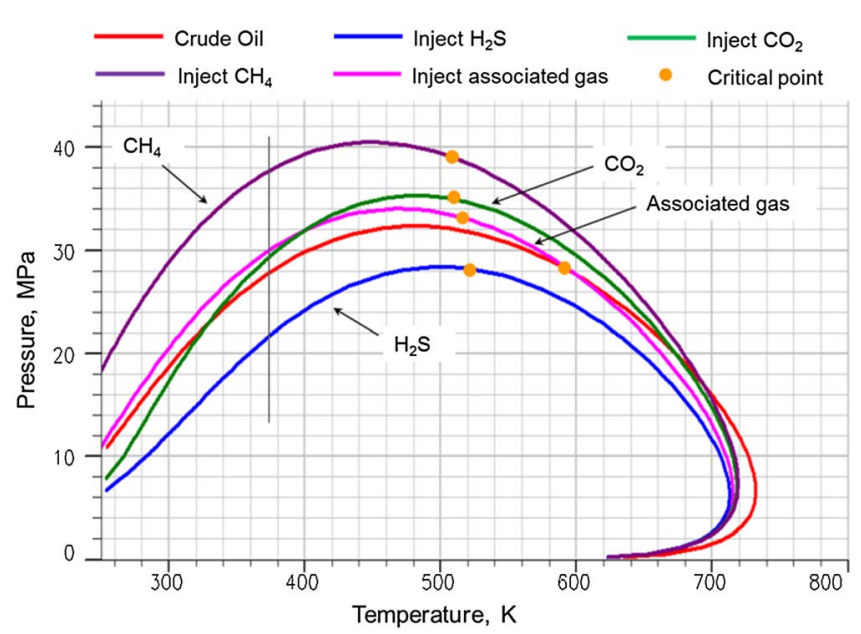

Fig. 3. The influence of gas injection on $P-T$ phase diagram (injection gas mole fraction $f=0.3$ ).

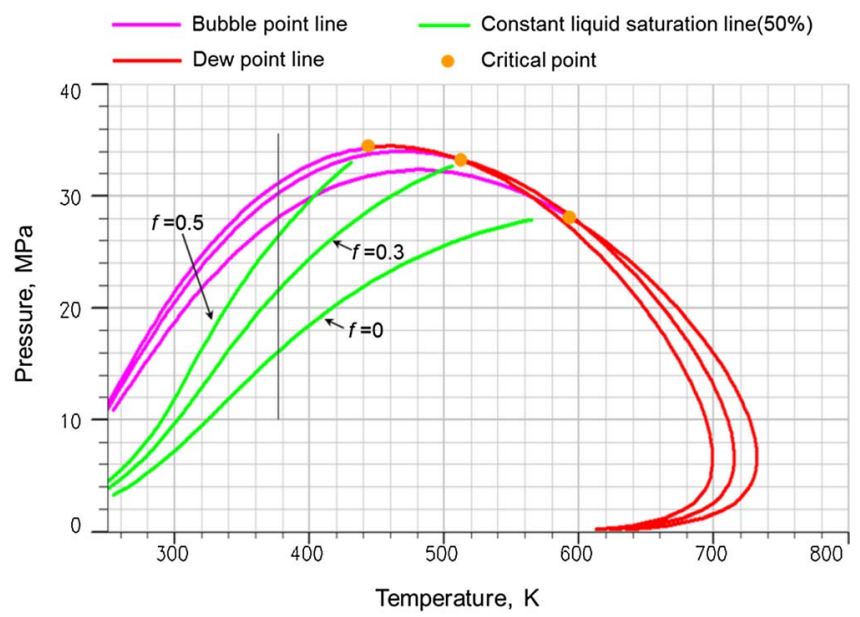

Fig. 4. The influence of injection gas mole fraction on $P-T$ phase diagram.

include slim-tube experiment, rising bubble method and vanishing interfacial tension method (Zhang et al., 2016). The rising bubble method and the vanishing interfacial tension method do not have the proper interactions of flow with phase behavior necessary to develop multi-contact miscibility. Slim-tube experiment, which uses actual reservoir fluids, can provide a reliable estimate and now is regarded as the standard procedure for predicting MMP. The crude oil of $\mathrm{K}$ oilfield displaced by the associated sour gas in the slim-tube is conducted at various pressures. The recovery at $1.2 \mathrm{PV}$ injectant against the pressure is plotted in Figure 7. It shows that the MMP of the associated sour gas is $28 \mathrm{MPa}$. Since slim-tube experiment is expensive and time consuming in practice, we resort to the analytical method, such as mixing-cell method (Abiodun et al., 2012), to analyze the effect of injection gas composition on MMP. In mixing-cell method, repeated contacts of equilibrium gas and oil with fresh gas and oil are made until the

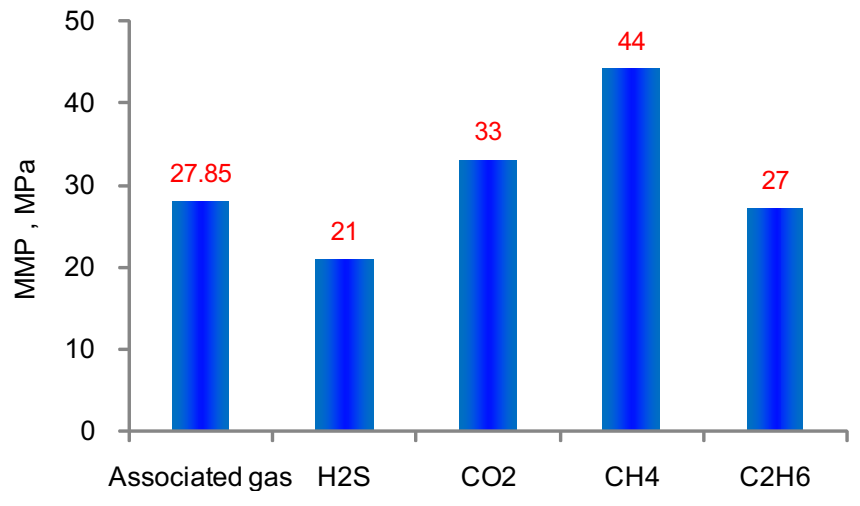

Fig. 5. The MMP of different injection gas composition calculated by the mixing-cell method.

key tie line is found. The advantage of the mixing-cell method is that it is very fast and the result also is reliable. The MMP of the associated sour gas calculated by mixingcell method is $27.85 \mathrm{MPa}$. Compared to the slim-tube experiment result of $28 \mathrm{MPa}$, a relative error of $0.5 \%$ supports the reliability and correctness of the mixing-cell method. On the basis, the MMP of different injection gas composition were calculated by mixing-cell method to determine their miscible ability and the result is shown in Figure 5. From Figure 5, it can be easily found that the miscible ability decrease in the following order: $\mathrm{H}_{2} \mathrm{~S}, \mathrm{C}_{2} \mathrm{H}_{6}$, associated sour gas, $\mathrm{CO}_{2}$ and $\mathrm{CH}_{4}$. The MMP of $\mathrm{H}_{2} \mathrm{~S}$ has the minimum value of $21 \mathrm{MPa}$ and that of $\mathrm{CH}_{4}$ has the maximum value of $44 \mathrm{MPa}$. As the associated sour gas consists mainly of $59.03 \% \mathrm{CH}_{4}$ and contains $17.42 \% \mathrm{H}_{2} \mathrm{~S}$ and $4.92 \% \mathrm{CO}_{2}$, the miscible ability is in between $\mathrm{CH}_{4}$ and $\mathrm{H}_{2} \mathrm{~S}$.

Understanding the impact of the gas compositional changes on the MMP is essential to optimal design of field-wide pressure management. In order to evaluate the effect of sour components $\left(\mathrm{H}_{2} \mathrm{~S}\right.$ and $\left.\mathrm{CO}_{2}\right)$ in the associated sour gas on MMP, the MMP of various levels of sour gas fraction were calculated by the mixing-cell method and the result is shown in Figure 6. A sour component fraction of 1 means the injectant is the original associated sour gas while a sour component fraction of zero means the corresponding sour component is excluded completely and other components are normalized. Figure 6 shows that the lower the sour gas component fraction, the greater the MMP. In other words, the miscible ability of associated sour gas decreases with the decrease of its sour component fraction. Re-injecting associated sour gas directly without eliminating its sour component is more likely to achieve miscible displacement. It also can be found that eliminating $\mathrm{H}_{2} \mathrm{~S}$ from the original associated sour gas has greater effect on miscible ability than eliminating $\mathrm{CO}_{2}$. This is due to the fact that $\mathrm{H}_{2} \mathrm{~S}$ has greater miscible ability and larger content in the associated sour gas of $\mathrm{K}$ oilfield than $\mathrm{CO}_{2}$.

\subsection{Miscible mechanism of associated sour gas injection}

To gain understanding about the miscible mechanism of sour gas injection, we resort to slim-tube simulation based on the Eclipse compositional simulator (E300) developed 


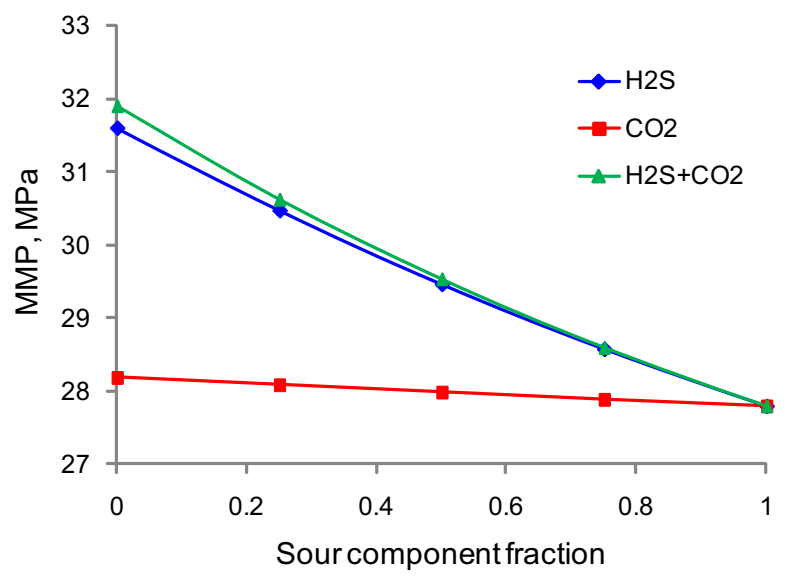

Fig. 6. The effect of sour component fraction on MMP calculated by the mixing-cell method.

by Schlumberger. The composition of components and their critical parameters of EOS shown in Table 1 are inputted into the Eclipse model. The grid size is $1000 \times 1 \times 1$ and the corresponding block dimensions are $0.001 \mathrm{~m}, 0.01 \mathrm{~m}$ and $0.01 \mathrm{~m}$. The injector is located at the first grid and the producer is located at the last grid. The porosity is $6 \%$ and the permeability is $10 \times 10^{-3} \mu^{2}$. The pressure drop across the slim-tube is ignored and the capillary pressure between oil and gas was zero. The gas was injected at the rate of $0.024 \mathrm{~m}^{3} / \mathrm{h}$. Before conducting slim-tube displacement experiments to investigate the miscible mechanism of sour gas injection, the Eclipse model was validated by comparing the oil recovery between slim-tube experiment data and simulation results as shown in Figure 7. It shows that the oil recovery obtained by Eclipse model is consistent with that of slim-tube experiment under the same pressure, which verifies the reliability of the Eclipse model.

Figures $8-10$ show the profiles within the slim-tube for the displacement by associated sour gas with $0.4 \mathrm{PV}$ of associated sour gas injected at a pressure $28.2 \mathrm{MPa}$ (just above its MMP). Figure 8a shows that three zones that are gas zone, transition zone and oil zone are formed in the slim-tube. Gas zone and oil zone only contain a single phase, that is, vapor phase or liquid phase. Therefore, the interfacial tension in these zones is zero. Transition zone contains vapor phase and liquid phase. As can be seen in Figure 8b, the interfacial tension decreases, reaches a minimum and then increases down the slim-tube in the transition zone. The middle position of the transition zone, where the interfacial tension reaches minimum, is closest to miscibility. The mechanism of crude oil displaced by associated sour gas is not either the condensing-gas drive mechanism or the vaporizing-gas drive alone. Instead, it shows a combined condensing/vaporizing type. The middle position seems to be the leading edge of vaporizing-gas drive mechanism and be the trailing edge of condensing-gas drive mechanism. The middle position divided the transition zone into two regions: vaporizing zone and condensing zone. Figure $8 \mathrm{~b}$ also shows that the vaporizing zone is slightly larger than the condensing zone. The vaporizing zone

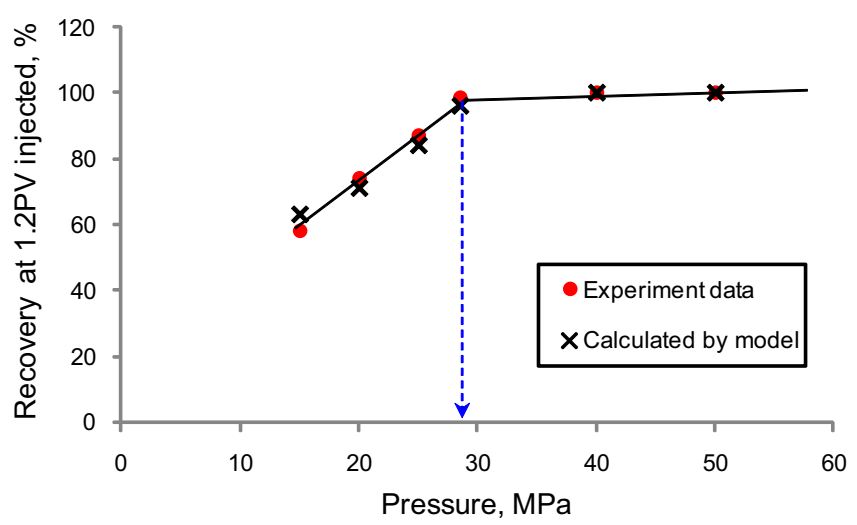

Fig. 7. The comparison of recovery between slim-tube experiment data and simulation results.

extends from grid 327 to grid 397, a total of 70 grids, while the condensing zone extends from grid 398 to grid 458 , a total of 60 grids. It means that though the displacement of crude oil by associated sour gas is a combined condensing/vaporizing mechanism, the vaporization part of mechanism is slightly stronger than the condensation part of mechanism. The viscosity and density of vapor phase and liquid phase are closest approach each other but don't converge to the same value at the point where the interfacial tension reaches minimum as shown in Figure 9. It should be pointed out that even though the displacement pressure is above the MMP, the interfacial tension at the middle position of the transition zone is 0.001 , not zero. In other words, the true miscibility was not achieved. Instead, it is kind of near miscibility. This is the reason why the viscosity and density of vapor phase and liquid phase at the middle position are very close to each other but don't converge to the same value.

Components profiles within slim-tube as shown in Figure 10 indicate the formation process of the combined condensing/vaporizing mechanism during the displacement of crude oil by associated sour gas. The light intermediates, such as $\mathrm{C}_{2-6}, \mathrm{H}_{2} \mathrm{~S}$ and $\mathrm{CO}_{2}$, condense into the crude oil as the associated sour gas contact the crude oil. This can be reasonably extrapolated from Figure 10b which shows that the mole fraction of light intermediates is higher than that of the original crude oil. Meanwhile, the middle intermediates, such as $\mathrm{C}_{7-20}$, vaporize into the vapor as shown in Figure 10c that the mole fraction of middle intermediates is lower than that of the original crude oil. At first the condensation of the light intermediates causes the oil lighter and then the vaporization of the middle intermediates causes the oil heavier. This is the reason why the miscibility happened in the middle of transition zone.

\subsection{The effect of pressure on miscibility}

In order to investigate the effect of pressure on miscibility, the displacements of crude oil with associated sour gas were simulated in slim-tube at various pressures. Figure 11a shows the profiles within slim-tube after $0.4 \mathrm{PV}$ of associated sour gas was injected at pressure of $33 \mathrm{MPa}$. As can 


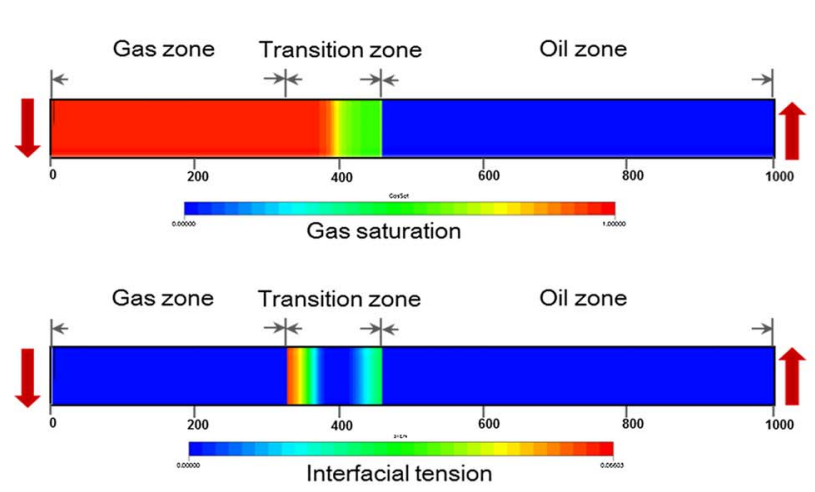

(a)

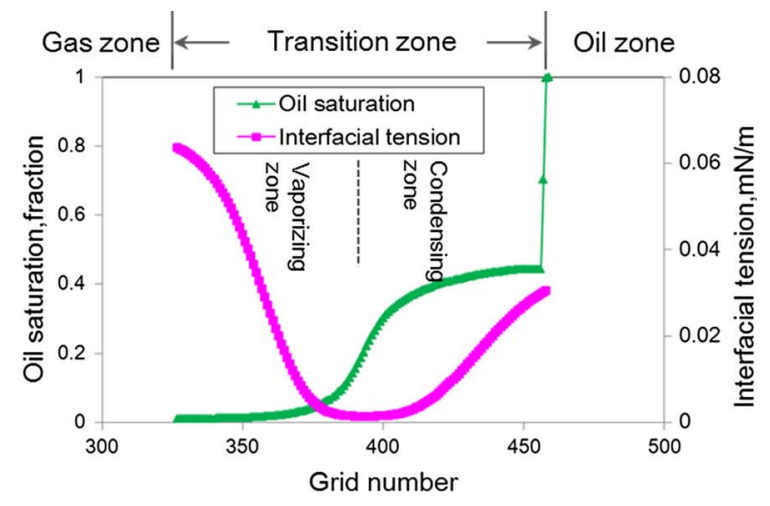

(b)

Fig. 8. Saturation and interfacial tension profile within the slim-tube for the displacement of crude oil by associated sour gas.

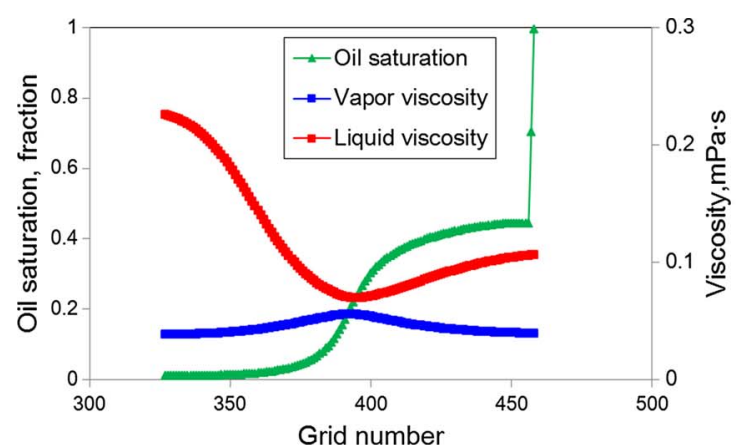

(a) Viscosity

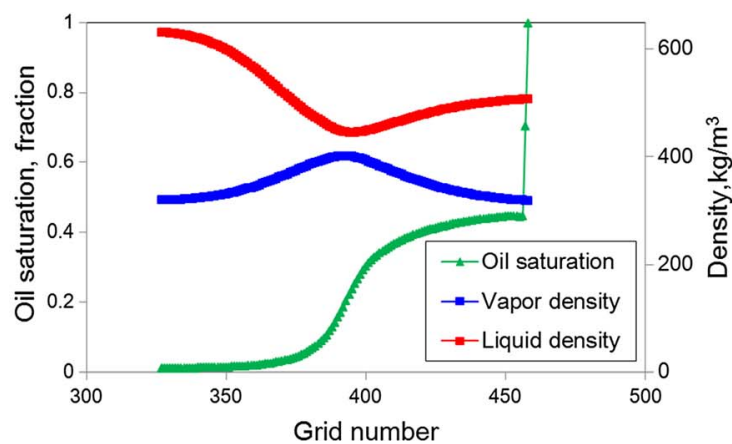

(b) Density

Fig. 9. Viscosity and density profile within slim-tube for the displacement of crude oil by associated sour gas.

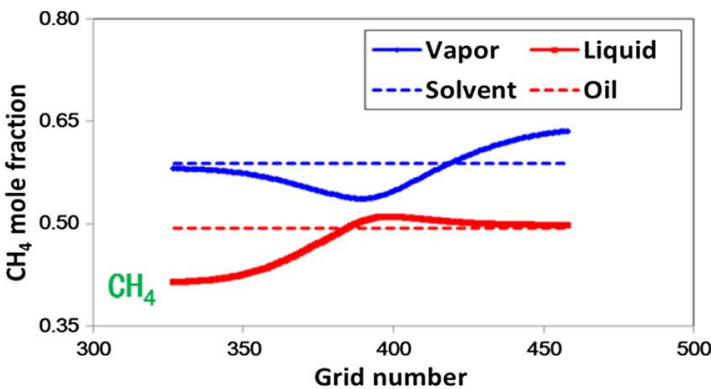

(a)

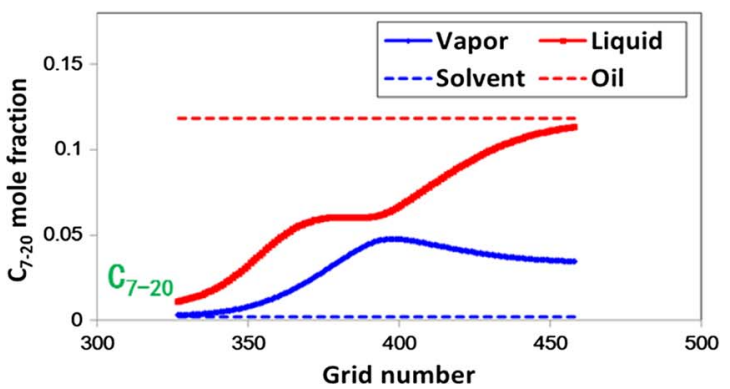

(c)

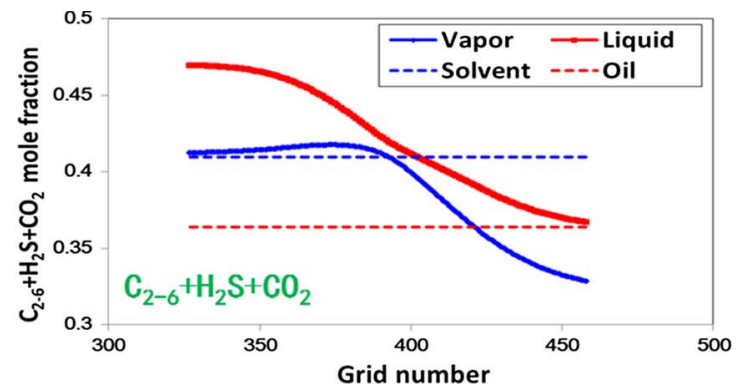

(b)

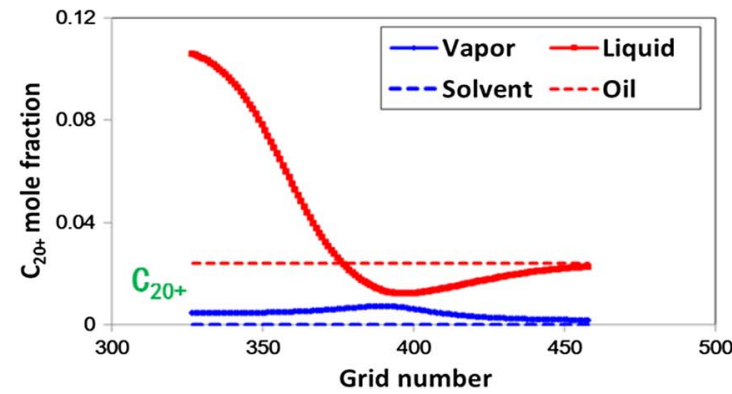

(d)

Fig. 10. Components profiles within slim-tube for the displacement of crude oil by associated sour gas. 


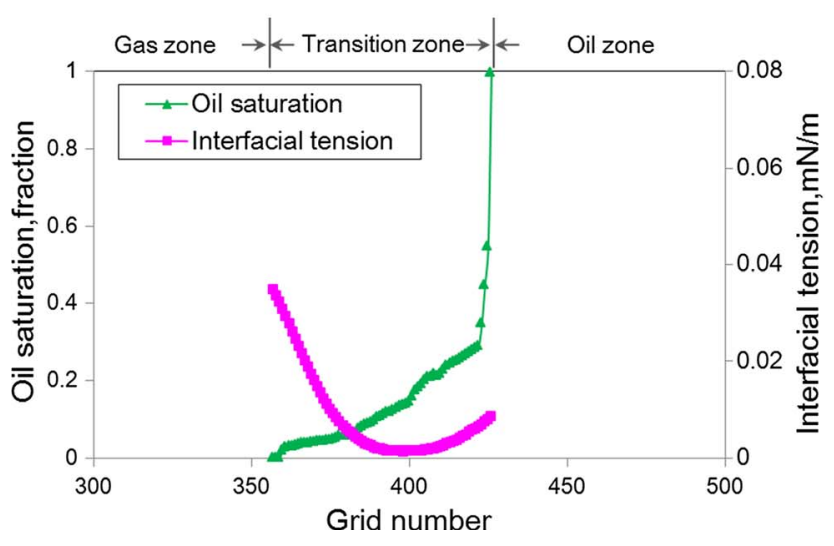

(a)

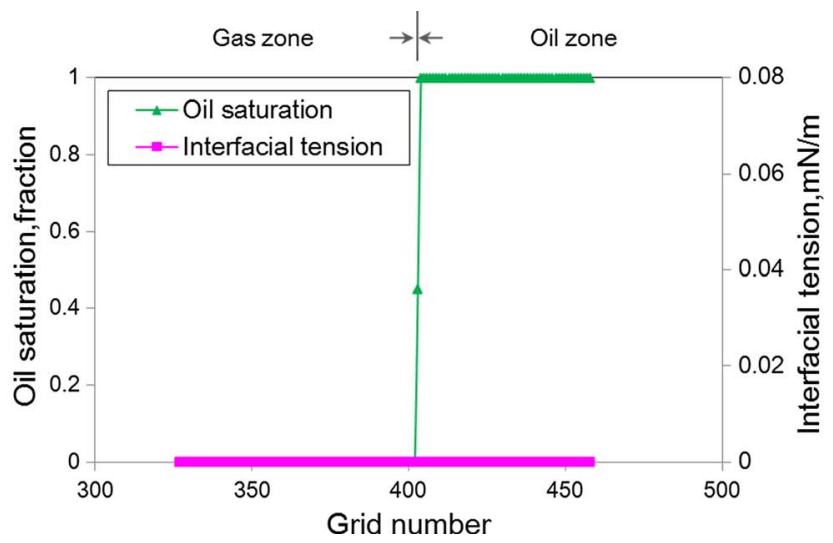

(b)

Fig. 11. The effect of pressure on miscibility with associated sour gas injection. (a) $P=33 \mathrm{MPa}$, (b) $P=36 \mathrm{MPa}$.

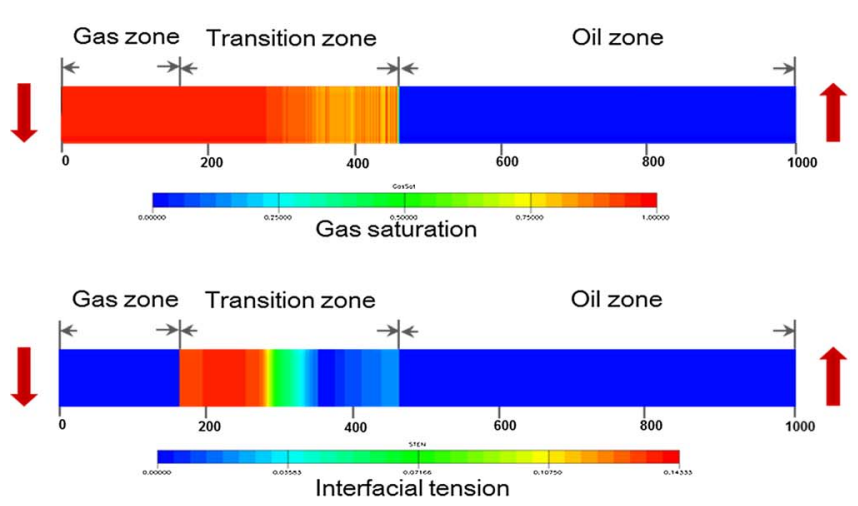

(a)

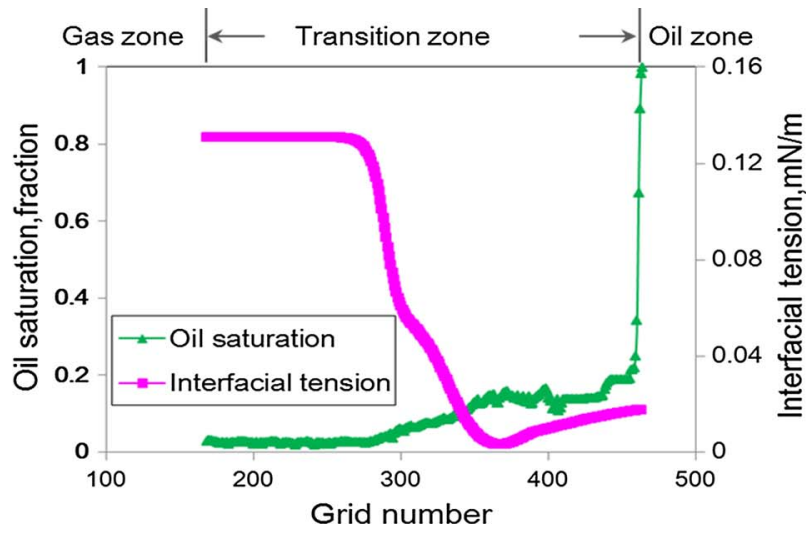

(b)

Fig. 12. Saturation and interfacial tension profile within slim-tube for the displacement of crude oil by sweet gas.

be seen in Figure 11a, the displacement of crude oil by associated sour gas at pressure of $33 \mathrm{MPa}$ also shows a combined condensing/vaporizing mechanism, very similar to that of at pressure of $28.2 \mathrm{MPa}$, but the transition zone at pressure of $33 \mathrm{MPa}$ is much smaller than that of at pressure of 28.2 MPa. For instance, the transition zone extends from grid 328 to grid 458, a total of 130 grids, at pressure of $28.2 \mathrm{MPa}$; nevertheless, it just extends from grid 357 to grid 426 , a total of 69 grids, at pressure of $33 \mathrm{MPa}$. It is also worth noting that the interfacial tension at the middle position of the transition zone is very small but not zero when the pressure is $33 \mathrm{MPa}$, similar to that of at pressure of 28.2 $\mathrm{MPa}$. That is, the true miscibility was not achieved even though the displacement pressure is already above the MMP. The simulations result shows that the near miscibility rather than true miscibility was achieved during displacement by the combined condensing/vaporizing mechanism. Figure 11b shows that the transition zone disappeared when the pressure increased to $36 \mathrm{MPa}$, which means the injectant has become first-contact miscible with the crude oil.

\subsection{The effect of injected gas composition on miscibility}

In order to investigate the effect of injected gas composition on miscibility, the displacements of crude oil with different solvents were simulated in slim-tube. The associated gas is sour containing $17.42 \% \mathrm{H}_{2} \mathrm{~S}$ and $4.92 \% \mathrm{CO}_{2}$. The sweet gas is defined as the associated sour gas with eliminating its sour component $\left(\mathrm{H}_{2} \mathrm{~S}\right.$ and $\left.\mathrm{CO}_{2}\right)$. Figure 6 shows that the MMP of sweet gas is about 31.9 MPa. Figure 12 shows the saturation and interfacial tension profile within the slim-tube for the displacement by sweet gas. These profiles, again at $0.4 \mathrm{PV}$ of gas injected, were generated during the displacement with the pressure of $32.3 \mathrm{MPa}$, just above its MMP. Figure 12 indicates that the displacement of crude oil by sweet gas also shows a combined condensing/ vaporizing mechanism. Unlike the associated sour gas, the vaporizing zone is significantly larger than the condensing zone during the displacement by sweet gas, that is, the vaporizing-gas drive mechanism is significantly stronger than the condensing-gas drive mechanism during the 


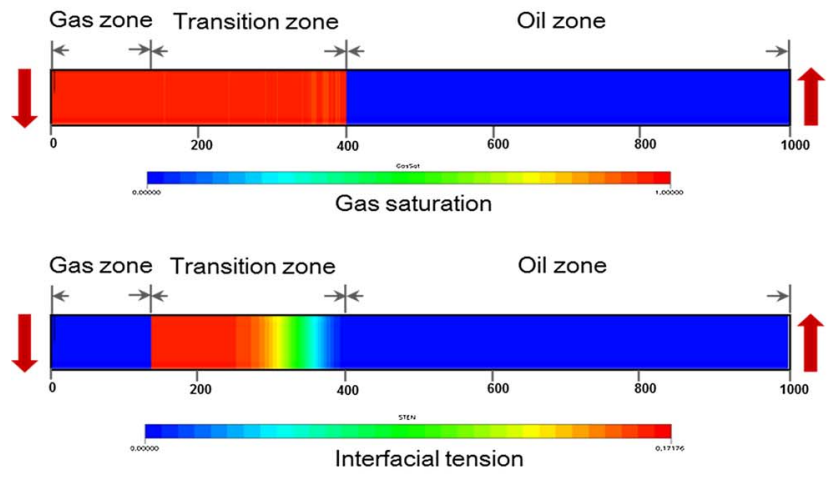

(a)

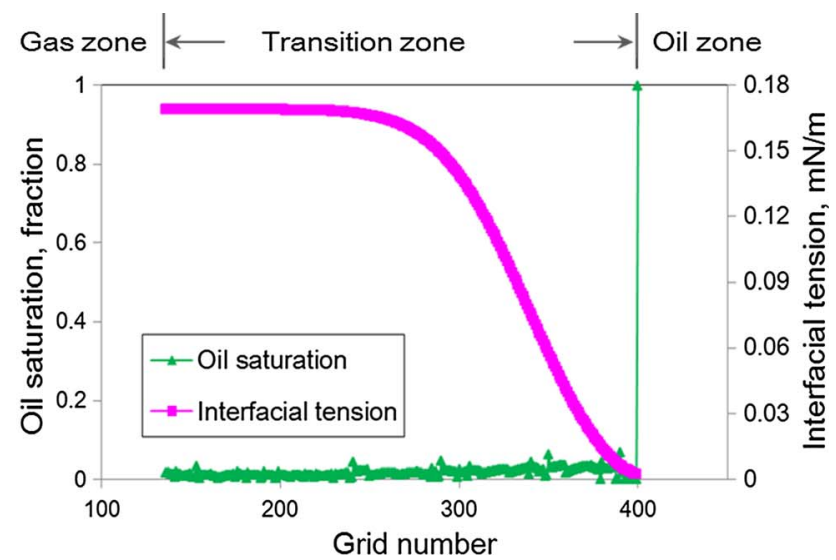

(b)

Fig. 13. Saturation and interfacial tension profile within slim-tube for the displacement of crude oil by $\mathrm{CH}_{4}$.

displacement by sweet gas. For instance, the vaporizing zone extends from grid 168 to grid 353, a total of 185 grids, while the condensing zone extends from grid 354 to grid 457, a total of 103 grids. Figure 5 shows that the MMP of $\mathrm{CH}_{4}$ is about $44 \mathrm{MPa}$. Figure 13 shows the saturation and interfacial tension profile within slim-tube after $0.4 \mathrm{PV}$ of $\mathrm{CH}_{4}$ was injected at pressure of $44.5 \mathrm{MPa}$. It can be easily found that the displacement of crude oil by $\mathrm{CH}_{4}$ is pure condensing-gas drive mechanism.

\section{Conclusion}

The following conclusions can be summarized from the results of this work:

1. The two-phase region becomes narrower after injecting $\mathrm{H}_{2} \mathrm{~S}$ and becomes wider after injecting $\mathrm{CH}_{4}$. The injection of $\mathrm{H}_{2} \mathrm{~S}$ can reduce the bubble point pressure of crude oil and therefore is beneficial to prevent the crude oil degassing; nevertheless, the injection of $\mathrm{CO}_{2}$ has little effect on it.

2. The miscible ability decrease in the following order: $\mathrm{H}_{2} \mathrm{~S}, \mathrm{C}_{2} \mathrm{H}_{6}$, associated sour gas, $\mathrm{CO}_{2}$ and $\mathrm{CH}_{4}$. The miscible ability of associated sour gas decreases with the decrease of its sour component fraction. Reinjecting associated sour gas directly without eliminating its sour component is more likely to achieve miscible displacement.

3. The mechanism of crude oil displaced by associated sour gas and sweet gas both show a combined condensing/vaporizing type, with miscible zone in the middle of transition zone. Unlike the associated sour gas, the vaporizing-gas drive mechanism is significantly stronger than the condensing-gas drive mechanism during the displacement by sweet gas.

4. The transition zone decreases with increasing pressure and it would disappear when the injectant becomes first-contact miscible with the crude oil.
Acknowledgments. This work was supported by the Major Projects of China (2017ZX05030).

\section{References}

Abiodun M., Shameem S., Habib M., Bob L. (2012) A new look at the minimum miscibility pressure (MMP) determination from slimtube measurements, Proceedings of the Eighteenth SPE Improved Oil Recovery Symposium, Oklahoma, USA, SPE 153383.

Arne S., Norsk H., Leonid S. (2000) Gas injection in Paleo oil zone, Proceedings of SPE Annual Technical Conference and Exhibition, Dallas, Texas, SPE 62996.

Chen H. (1995) Gas injection in the Safah field, Oman, Proceedings of SPE Middle East Oil, Bahrain, SPE29805.

Chen W., Tang Y., Liang T., Sun L., Liu W., Chen Z. (2011) Mechanism study of supercritical $\mathrm{CO}_{2}$ 's dynamic miscible flooding process, Drill. Prod. Technol. 34, 3, 77-80.

Chueh P.L., Prausnitz J.M. (1967) Vapour-liquid equilibria at high pressures, calculation of partial molar volume in nonpolar liquid mixtures, AIChE 13, 6, 1099-1113.

Guo P., Sun L., Sun L., Li S., Peng P., Yue L. (2000) Influences of injection gas on physical behavior of crude, J. Southwest Pet. Inst. 22, 3, 57-64.

Johns R.T., Fayers F.J., Orr F.M. (1994) Effect of gas enrichment and dispersion on nearly miscible displacements in condensing/vaporizing drives, SPE Adv. Technol. Ser. 2, 2, 26-34.

Knut U., Lars H. (2002) Miscible gas injection in fractured reservoirs, Proceedings of SPE/DOE Improved Oil Recovery Symposium, Tulsa, Oklahoma, USA, SPE 75136.

Kulkarni M.M., Rao D.N. (2005) Experimental investigation of miscible secondary gas injection, Proceedings of SPE Annual Technical Conference and Exhibition, Dallas, Texas, USA, SPE 95975.

Li M., Shan W., Liu X., Shang G. (2006) Laboratory study on miscible oil displacement mechanism of supercritical carbon dioxide, Acta Petrolei Sinica 27, 3, 80-83.

Meng F., Lei Q., Sun Y., He D. (2018) Law of $\mathrm{CO}_{2}$ immiscible front movement in low-permeability oil reservoir, J. Southwest Pet. Univ. (Sci. Technol. Ed.) 40, 3, 121-128. 
Murty C., Al-Khayat S. (1989) Gas injection in a saturated oil reservoir, Proceedings of SPE Middle East Oil Technical Conference and Exhibition, Manama, Bahrain, SPE 17991.

Obut S.T., Ertekin T., Geisbrecht R.A. (1986) A versatile phase equilibrium package for compositional simulation, Proceedings of 56th California Regional Meeting of the Society of Petroleum Engineers, Oakland, CA, SPE 15083.

Sabyrzhan D., Aizada A., Dave B., Mike S., Greg K., Tayo F., Phil B. (2010) Tengiz sour gas injection project, Proceedings of Caspian Carbonates Technology Conference, Atyrau, Kazakhstan, SPE 139851.

Soave G. (1972) Equilibrium constants from a modified RedlichKwong equation of state, Chem. Eng. Sci. 27, 1197-1203.

Stalkup F.I. (1987) Displacement behavior of the condensing/ vaporizing gas drive process, Proceedings of 62nd Annual Technical Conference and Exhibition, Dallas, TX, SPE 16715.

Tang Y., Sun L., Xiong J., Guo P., Wang Z., Zhang X. (2001) Study on the simulation calculation of complete $\mathrm{p}-\mathrm{x}$ phase diagram in miscible gas injection, J. South Pet. Inst. 23, 3, 40-43.

Tang Y., Sun L., Zhou Y., Li S., Guo P., Li Y. (2004) On evaluation method of miscible gas-flooding mechanism, Xinjiang Pet. Geol. 25, 4, 414-417.

Tang Y., Sun L., Zhou Y., Li S., Sun L., Du Z. (2005) Mechanism evaluation of condensing/vaporizing miscible flooding with hydrocarbon rich gas injection, Pet. Explor. Dev. 32, 2, 133-136.

Teletzke G.F., Patel P.D., Chen A.L. (2005) Methodology for miscible gas injection EOR screening, Proceedings of SPE
International Improved Oil Recovery Conference in Asia Pacific, Kuala Lumpur, Malaysia, SPE 97650.

Xu A., Mu L., Zhao L., Wang C. (2015) Analysis of miscibility of high sour component $\left(\mathrm{H}_{2} \mathrm{~S}\right.$ and $\left.\mathrm{CO}_{2}\right)$ content gas flooding under abnormal reservoir pressure, Proceedings of Asia Pacific Oil \& Gas Conference and Exhibition, Nusa Dua, Bali, Indonesia, SPE 176591.

Yang S., Wei J. (2004) Reservoir physics, 1st edn., Petroleum Industry Press, Beijing.

Zakaria A. (2011) Optimizing simulation studies for miscible gas injection process using horizontal wells, Proceedings of SPE Enhanced Oil Recovery Conference, Kuala Lumpur, Malaysia, SPE 144069.

Zhang C., Fan Z., Xu A., Zhao L., Zhao L. (2016) The influence of sour gas on MMP and the composition optimization for solution gas reinjection in volatile oil reservoir, Sci. Technol. Eng. 16, 11, 54-58.

Zhang P., Brodie J., Daae V., Erbas D., Duncan E. (2013) BP North sea miscible gas injection projects review, Proceedings of SPE Offshore Europe Oil and Gas Conference and Exhibition, Aberdeen, UK, SPE 166597.

Zhu L., Liao X., Zhao X., Chen Z., Chen Y., Wang H. (2015) Effects of different gases on hydrocarbon miscible displacements, J. Shaanxi Univ. Sci. Technol. 33, 5, 100-105.

Zick A.A. (1986) A combined condensing/vaporizing mechanism in the displacement of oil by enriched gases, Proceedings of Annual Technical Conference and Exhibition, New Orleans, LA, SPE 15493. 